\title{
SURVEY IDENTIFIKASI PULAU-PULAU TENGGELAM DI TELUK JAKARTA
}

\section{IDENTIFICATION SURVEY OF SINKING ISLAND IN JAKARTA BAY}

\author{
Muhammad Ramdhan, Syahrial Nur Amri \& Dino Gunawan Priyambodo \\ Pusat Riset Kelautan, BRSDM - KKP \\ Jln. Pasir Putih 1 Ancol Jakarta; Telp/fax : +62 2164711583 \\ e-mail : m.ramdhan@kkp.go,id \\ Diterima: 14 Juni 2019 ; Perbaikan: 02 Juli 2019 ; Disetujui: 15 Agustus 2019
}

\begin{abstract}
ABSTRAK
Jakarta adalah kota pesisir yang memiliki area berbentuk kepulauan di wilayah Utara tepatnya di Kabupaten Kepulauan Seribu. Pulau-pulau ini merupakan aset daerah yang harus dijaga keberadaannya. Pulau dapat berfungsi sebagai sumber daya ekologis yang memberikan jasa lingkungan kepada wilayah sekitarnya. Penelitian ini akan mencoba mengidentifikasi pulau-pulau yang tenggelam yang ada di dalam area Teluk Jakarta. Tujuannya adalah memberikan informasi kepada khalayak umum tentang kondisi terkini pulau yang tenggelam, kemudian memberikan rekomendasi kepada pihak terkait untuk melakukan upaya restorasi pulau-pulau tersebut. Hal ini penting dilakukan agar pulau-pulau tersebut tidak hilang dari catatan sejarah dunia.
\end{abstract}

Kata kunci: Survey Lapangan, GPS, Identifikasi Pulau, Pulau tenggelam.

\section{ABSTRACT}

Jakarta is a coastal city that has an islands-shaped area in the North, precisely in the Thousand Islands District. These islands are regional assets that must be maintained. The island can function as an ecological resource that provides environmental services to the surrounding area. This research will try to identify the sinking islands in the Jakarta Bay area. The aim is to provide information to the general public about the current condition of the sinking island, then provide recommendations to relevant parties to make efforts to restore the islands. This is important so that the islands are not lost from world historical records.

\section{Keywords: Field Survey, GPS, Island Identification, Sinking Island.}

\section{PENDAHULUAN}

Indonesia disebut sebagai negara kepulauan terbesar di dunia yang memiliki 17.504 pulau dan luas 5,8 juta $\mathrm{km}^{2}$. Lebih dari 13.000 pulau merupakan Pulau-Pulau Kecil (PPK). Menurut UU Nomor 1 tahun 2014 tentang perubahan atas UU Nomor 27 Tahun 2007, pulau kecil adalah pulau dengan luas lebih kecil atau sama dengan $2.000 \mathrm{~km}^{2}$ beserta kesatuan ekosistemnya. Sebagai negara kepulauan, pulau kecil mempunyai arti penting dalam segi ekonomi, sosial, budaya maupun pertahanan keamanan. Sebagian penduduk Indonesia memanfaatkan pulau-pulau kecil untuk tempat tinggal dan sebagai sumber penghidupan. Pembangunan di pulau kecil akan mengentaskan kemiskinan sebagian penduduk (Dahuri, 2013).
Penduduk yang bermukim di PPK umumnya adalah penduduk di luar usia produktif seperti anak-anak dan orang tua, sedangkan para kaum mudanya rata-rata telah pindah ke sejumlah kota besar untuk mencari nafkah. Pulau kecil menyimpan berbagai sumber daya alam dan jasa-jasa lingkungan terdiri atas sumber daya dapat pulih (renewable resources) atau sering juga disebut sumber daya alam hayati dan sumber daya tidak dapat pulih (nonrenewable resources) atau disebut sumber daya alam non hayati. Secara umum, permasalahan yang dihadapi dalam pengelolaan PPK, antara lain: sebagian besar merupakan kawasan tertinggal, terbatasnya sarana dan prasarana dasar sepertilistrik, air, dan transportasi yang menghubungkan antar pulau, PPK terluar memiliki potensi konflik atas pelanggaran batas wilayah, dan masih terbatasnya data 
dan informasi mengenai pulau - pulau kecil untuk pengembangan pulau ke depan.

Pulau kecil di Indonesia mempunyai beberapa fungsi, yaitu secara politik, ekonomi dan ekologi. Secara politik pulau kecil mempunyai fungsi pertahanan dan keamanan terutama pulau-pulau kecil perbatasan dengan negara lain. Pulau kecil terluar merupakan titik penarikan batas wilayah negara dengan negara tetangga. Secara ekonomi, pulau kecil merupakan lokasi yang mempunyai produktifitas hayati tinggi, kegiatan wisata, mempunyai peluang besar untuk dikembangkan sebagai wilayah bisnis yang berbasis sumberdaya serta sebagai tempat tinggal. Secara ekologi, ekosistem pesisir dan laut PPK berperan mempengaruhi iklim global, siklus hidrologi dan bioekonomi, penyerap limbah, sumber plasma nutfah, sumber energi alternatif dan sistem penunjang kehidupan lainnya. Pemanfaatan ekologi secara ekonomi akan membuat pengelolaan pulau-pulau kecil secara berkelanjutan.

Pulau pulau kecil adalah potensi sumberdaya alam yang sangat berharga. Apalagi bila didukung dengan ekosistem yang memiliki produktifitas hayati yang tinggi seperti terumbu karang, padang lamun, hutan bakau, serta keanekaragaman hayati biota laut yang bernilai ekonomi tinggi. PPK yang berada di wilayah utara Jakarta memiliki Jasa-jasa lingkungan yang potensial untuk wisata bahari antara lain pantai yang indah, areal penyelaman, olah raga air dan areal rekreasi (Widodo, 2015). Investasi di PPK yang dilakukan oleh pemerintah maupun swasta merupakan bagian kegiatan pembangunan. Hal ini yang diharapkan mampu meningkatkan perekonomian dan memberikan multiplayer effect pada masyarakat. Pada sisi lain, partisipasi masyarakat dan peran pemerintah dalam menciptakan iklim yang kondusif merupakan jaminan kepastian berusaha bagi investor yang akan menanamkan modalnya di PPK.

Proses pembangunan yang begitu pesat di daratan
Jakarta memberikan ancaman penurunan muka tanah (land subsidence) yang signifikan. Penelitian Rochman dkk. (2004) menunjukkan bahwa Jakarta mengalami penurunan muka tanah maksimum sebesar $34,2 \mathrm{~cm} /$ tahun berdasarkan data pengamatan GPS periode 2000 - 2001 di titik Daan Mogot, dan berdasarkan pengukuran gravity tahun 2009-2010 mengkonfirmasi penurunan muka tanah di wilayah DKI Jakarta maksimum 14,4 cm/tahun (Setyawan dkk., 2015). Hal ini juga berdampak pada pulau-pulau kecil yang berada di Teluk Jakarta, ditambah dengan ancaman kenaikan muka air laut yang berdasarkan prediksi Anggraini dkk. (2012) bahwa di tahun 2030 di jakarta akan terjadi kenaikan muka air laut setinggi 2,88 m, sedangkan data pengamatan lapangan tahun 2004 - 2010 menunjukkan permukaan air laut di Muara Baru, Teluk Jakarta mengalami kenaikan setinggi $10 \mathrm{~cm}$ (Arifin dkk., 2014). Maka keberadaan pulau-pulau kecil di utara jakarta akan semakin terancam. Makalah ini akan menyajikan informasi beberapa pulau yang telah tenggelam dan terancam tenggelam di Teluk Jakarta.

\section{BAHAN DAN METODE}

Metode penelitian yang dilakukan dalam mengidentifikasi pulau tenggelam adalah dengan studi literatur dan melakukan wawancara dengan masyarakat untuk menggali informasi awal. Selanjutnya dilakukan observasi lapangan pada tanggal 16-17 Maret 2017. Dari informasi awal, didapat 5 pulau yang diduga sebagai pulau tenggelam yaitu: Pulau Nyamuk Besar/ Nirwana, Pulau Tala, Pulau Nusi, Pulau Ubi dan Pulau Dapur. Sebaran pulau-pulau kecil tersebut dapat dilihat pada Gambar 1.

Tim survei mengunjungi posisi pulau tersebut untuk mendokumentasikan kondisi terkini dari pulau tersebut. Juga dilakukan pengukuran kedalaman dengan memanfaatkan GPS fishfinder yang ada pada kapal survey. Tabel 1 menunjukkan lokasi koordinat pulau beserta waktu pelaksanaan survey.

Tabel 1. Daftar nama pulau dan waktu pelaksanaan survey

\begin{tabular}{llllll}
\hline No & Nama Pulau & \multicolumn{2}{c}{ Koordinat } & Tanggal & Waktu (WIB) \\
& & Lintang (LS) & Bujur (BT) & Survey & \\
\hline 1 & Nyamuk Besar/Nirwana & $06^{\circ} 01^{\prime} 55,36^{\prime \prime}$ & $106^{\circ} 50^{\prime} 59,75^{\prime \prime}$ & 16 Maret 2017 & $13: 20$ \\
2 & Tala & $06^{\circ} 00^{\prime} 27,69^{\prime}$ & $106^{\circ} 49^{\prime} 59,83^{\prime \prime}$ & 16 Maret 2017 & $14: 50$ \\
3 & Nusi & $05^{\circ} 59^{\prime} 15,37^{\prime}$, & $106^{\circ} 46^{\prime} 40,90^{\prime \prime}$ & 16 Maret 2017 & $15: 50$ \\
4 & Ubi & $05^{\circ} 59^{\prime} 54,63^{\prime \prime}$ & $106^{\circ} 44^{\prime} 30,62^{\prime \prime}$ & 16 Maret 2017 & $16: 25$ \\
5 & Dapur & $05^{\circ} 55^{\prime} 30,15^{\prime \prime}$ & $106^{\circ} 43^{\prime} 28,59^{\prime \prime}$ & 17 Maret 2017 & $9: 23$ \\
\hline
\end{tabular}




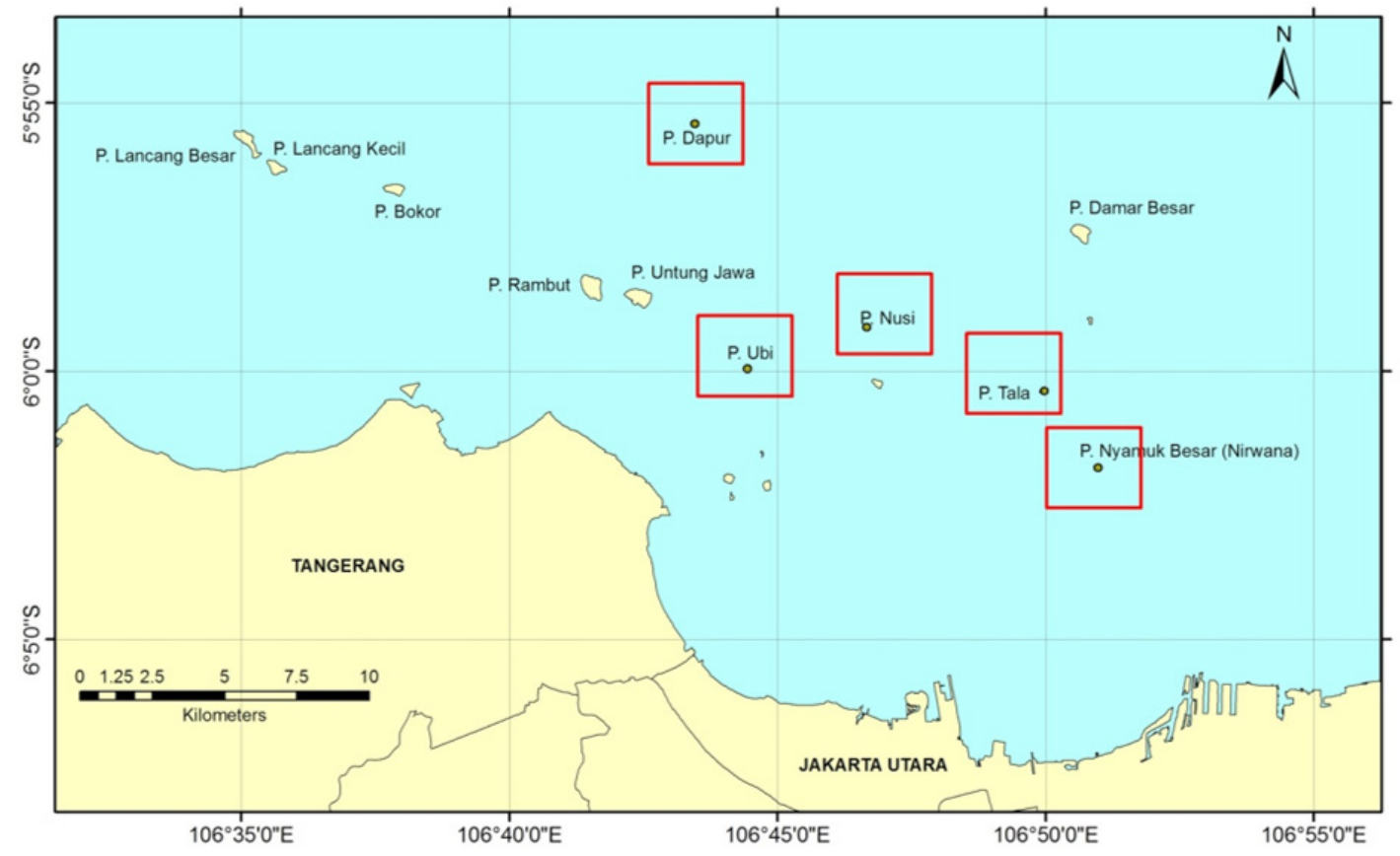

Gambar 1. Pulau-pulau yang diduga tenggelam di Teluk Jakarta (Husrin dkk, 2018).

Kondisi pasang surut air laut pada waktu nama-nama pulau di Indonesia pada koordinat $06^{\circ} 01^{\text {' }}$ pelaksanaan survey dapat dilihat pada Gambar 2. 57,72"LS; 10651’00,00”BT (Bakosurtanal, 1992). Gambar tersebut merupakan hasil observasi stasiun Pada waktu pengamatan lapangan hari Kamis, tanggal pasang surut BIG yang berada di pelabuhan Tanjung 16 Maret 2017 pukul 13.20 WIB hanya terlihat menara Priuk, data tersebut tersedia online pada situs http:// suar sebagai penanda navigasi pelayaran di lokasi www.ioc-sealevelmonitoring.org. Waktu pengambilan survey. Kondisi pulau saat ini telah menjadi gosong data umumnya berada pada saat kondisi paras air laut karang. Menurut nelayan setempat pulau tersebut sudah sedang surut.

\section{HASIL DAN PEMBAHASAN}

\section{Pulau Nyamuk Besar/Nirwana}

Pulau Nirwana terdaftar pada dokumen Gazetteer dari 30 tahun lalu tidak lagi ada di atas permukaan air laut.

Gambar 3 menunjukkan kondisi terkini perairan di sekitar Pulau Nyamuk Besar/Nirwana. Hasil interpretasi data kedalaman dari GPS fishfinder terlihat

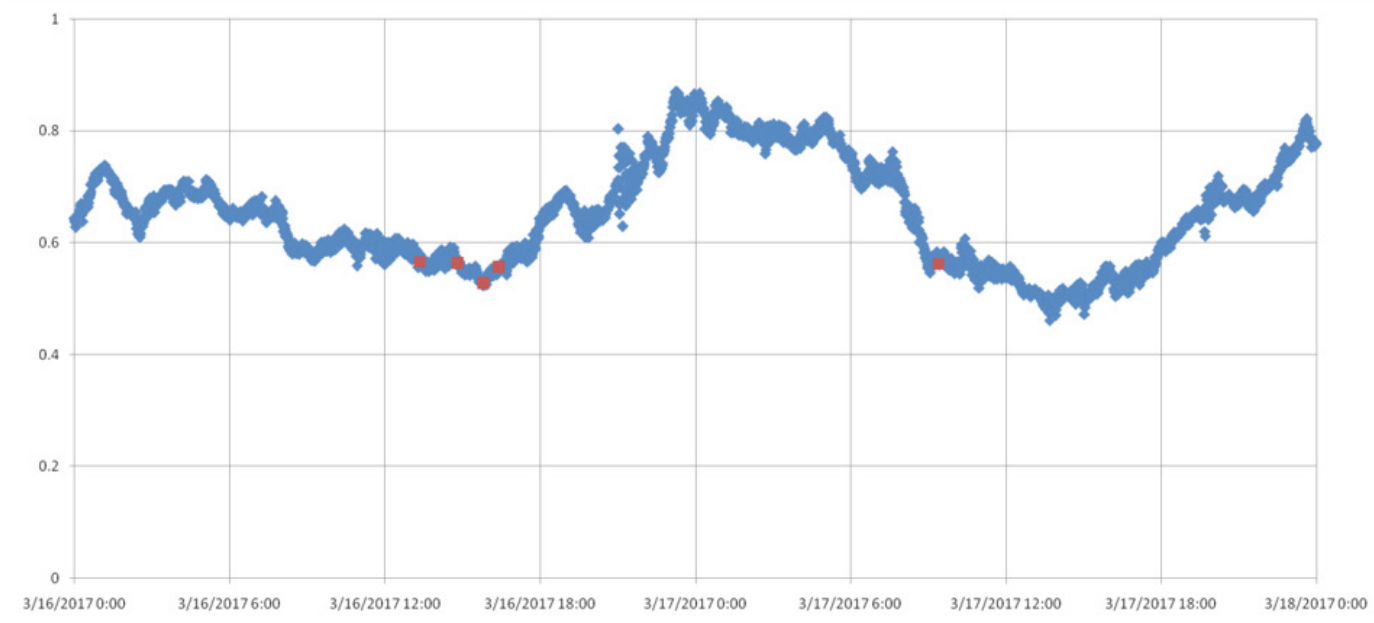

Gambar 2. Kondisi ketinggian muka air laut pada saat survey. Sumber : http://www.ioc-sealevelmonitoring.org 

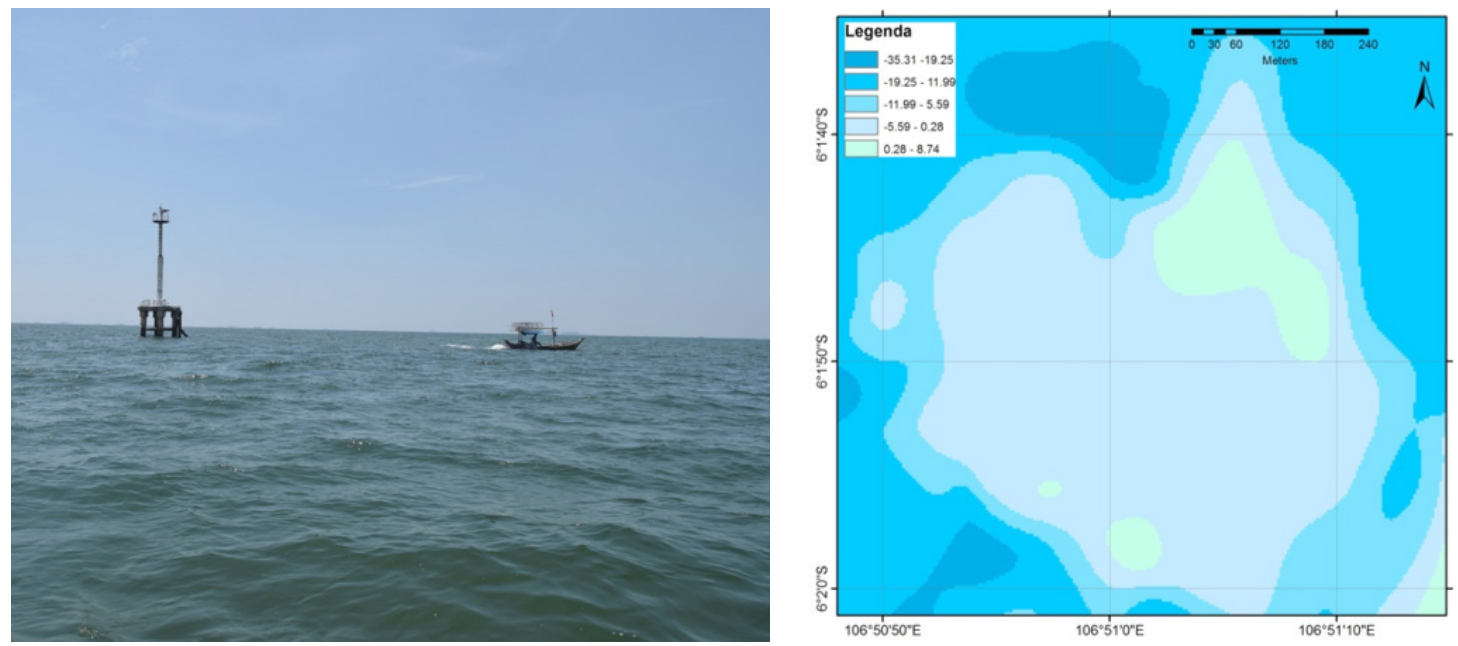

Gambar 3. Situasi dan kondisi kedalaman di sekitar lokasi Pulau Nirwana.

kedalaman rata-rata di pulau tersebut adalah $0-0,59$ meter. Pulau tersebut berbentuk bulat dengan diameter $\pm 500 \mathrm{~m}$.

\section{Pulau Tala}

Pulau Tala terdaftar pada dokumen Gazetteer nama-nama pulau di Indonesia dengan nama Pulau Talak pada koordinat $06^{\circ} 00^{\prime} 29,88^{\prime \prime}$ LS ; $106^{\circ} 49^{\prime} 58,80^{\prime \prime}$ BT (Bakosurtanal, 1992). Pada waktu pengamatan lapangan hari Kamis, tanggal 16 Maret 2017 pukul 14.50 WIB, daratan pulau masih terlihat namun telah terjadi abrasi yang telah mengikis sempadan pantai, hal ini menyebabkan bangunan yang ada di pinggir pulau rusak berat (Gambar 4.). Terlihat menara suar sebagai penanda navigasi pelayaran di lokasi survei. Kenaikan muka air lebih dari 2 meter akan menyebabkan seluruh Pulau Tala tenggelam di masa depan.

\section{Pulau Nusi}

Pada waktu pengamatan lapangan di lokasi Pulau Nusi hari Kamis, tanggal 16 Maret 2017 pukul 15.50 WIB, hanya terlihat menara suar sebagai penanda navigasi pelayaran di lokasi survey. Menurut nelayan setempat 10 tahun lalu kedalaman laut di sekitar pulau
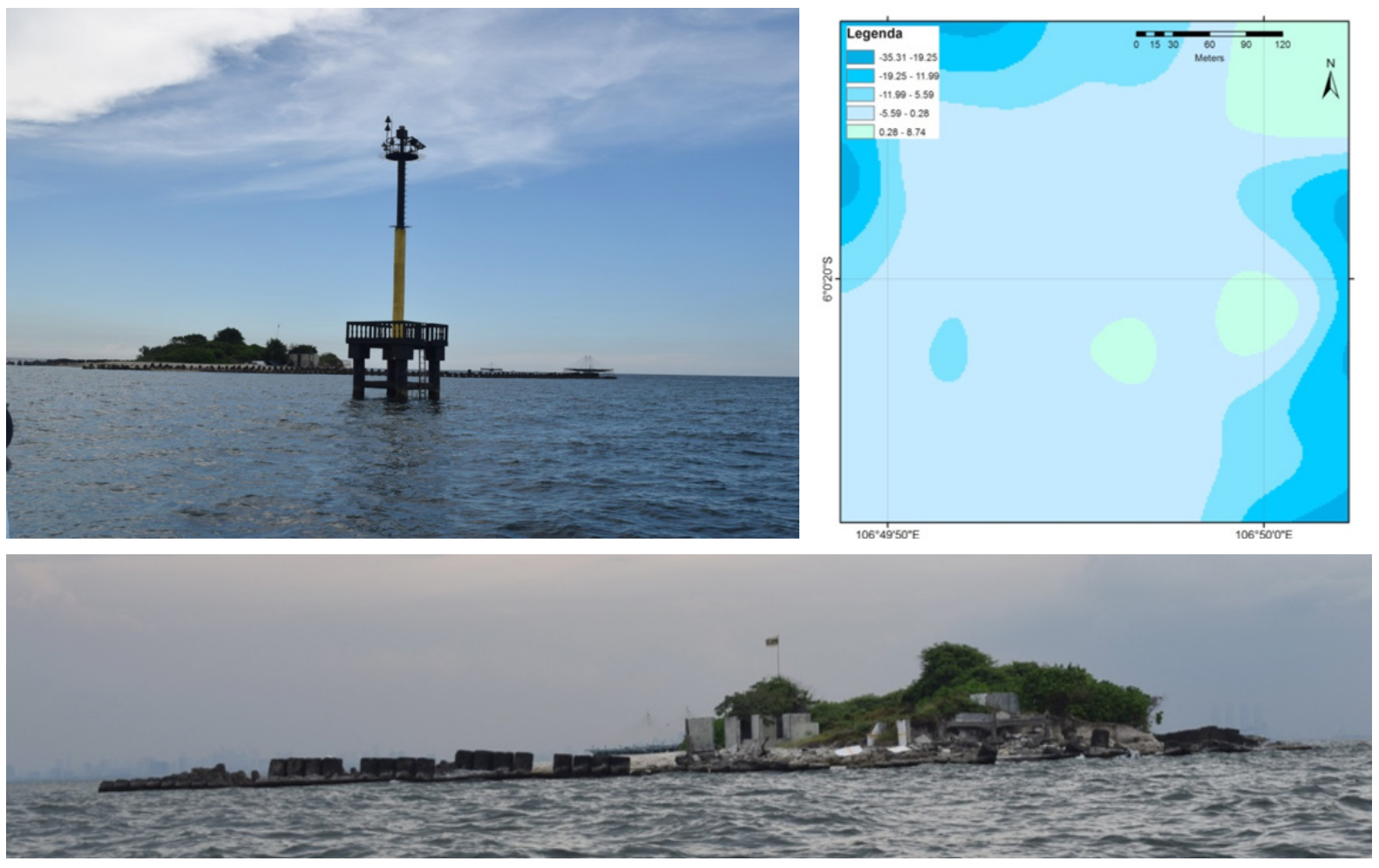

Gambar 4. Situasi dan kondisi kedalaman di sekitar lokasi Pulau Tala. 

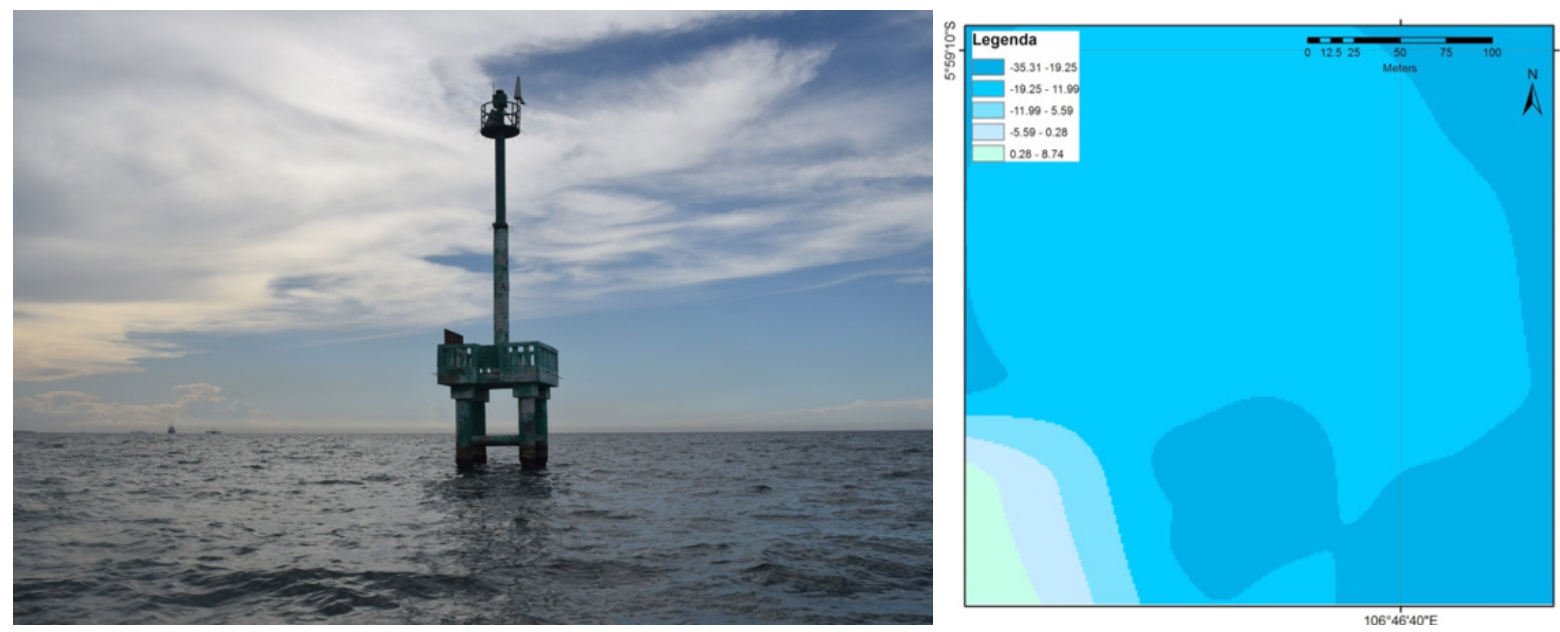

Gambar 5. Situasi dan kondisi kedalaman di sekitar lokasi Pulau Nusi.

itu tidak lebih dari $1 \mathrm{~m}$. Saat ini dari hasil pengukuran GPS fishfinder didapatkan rentang kedalaman antara 6- 12 m (Gambar 5.).

\section{Pulau Ubi}

Pulau Tala terdaftar pada dokumen Gazetteer nama-nama pulau di Indonesia dengan nama Pulau Ubi Besar pada koordinat $06^{\circ} 00^{\prime} 00,00^{\prime \prime} \mathrm{LS}$; 106 43'59,88”BT (Bakosurtanal, 1992). Pada waktu pengamatan lapangan hari Kamis, tanggal 16 Maret 2017 pukul 16.25 WIB, hanya terlihat menara suar sebagai penanda navigasi pelayaran di lokasi survei Menurut nelayan setempat pada tahun 1995 fisik pulau masih terlihat. Pulau ini memiliki kisah sejarah sebagai tempat eksekusi dari pemimpin DI/TII Kartosuwiryo (Zon, 2012).

\section{Pulau Dapur}

Pulau Dapur terdaftar pada dokumen Gazetteer nama-nama pulau di Indonesia pada koordinat $05^{\circ} 54^{\prime}$ 59,76"LS; 106²2'59,76"BT (Bakosurtanal, 1992). Pada waktu pengamatan lapangan hari Jum'at, tanggal 17 Maret 2017 pukul 09.23 WIB, hanya terlihat menara suar sebagai penanda navigasi pelayaran di lokasi survei. Menurut nelayan setempat pulau sudah tidak ada, sekitar 3 tahun lalu masih terlihat gundukan pasir dan penyu bertelur di sekitar area bekas pulau.

\section{KESIMPULAN DAN SARAN}

Pulau-pulau kecil di utara Teluk Jakarta terancam keberadaannya karena fenomena penurunan muka air tanah dan kenaikan permukaan air laut. Bukti nyata tenggelamnya pulau telah berhasil direkam dalam survey lapangan di 5 pulau. Pulau Nyamuk Besar/ Nirwana, Pulau Tala, Pulau Nusi, Pulau Ubi dan Pulau Dapur teridentifikasi sebagai pulau yang tenggelam di Teluk Jakarta. Substrat bekas pulau teridentifikasi berada pada kedalaman 6-12 meter dibawah permukaan laut.

Pemerintah daerah perlu memperhatikan kondisi pulau-pulau tenggelam ini. Perlu dilakukan studi lanjut untuk mengkaji upaya restorasi pulau agar dapat kembali dimanfaatkan sumberdaya lahannya untuk keperluan wisata atau keperluan pembangunan lainnya yang dapat memberikan manfaat lebih bagi masyarakat
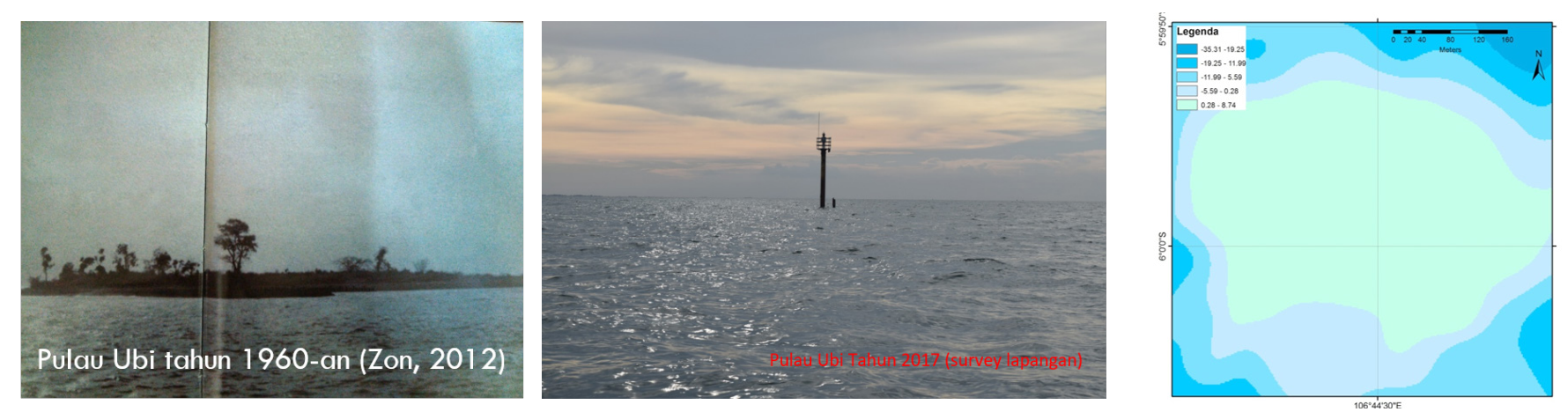

Gambar 6. Situasi dan kondisi kedalaman di sekitar lokasi Pulau Ubi. 

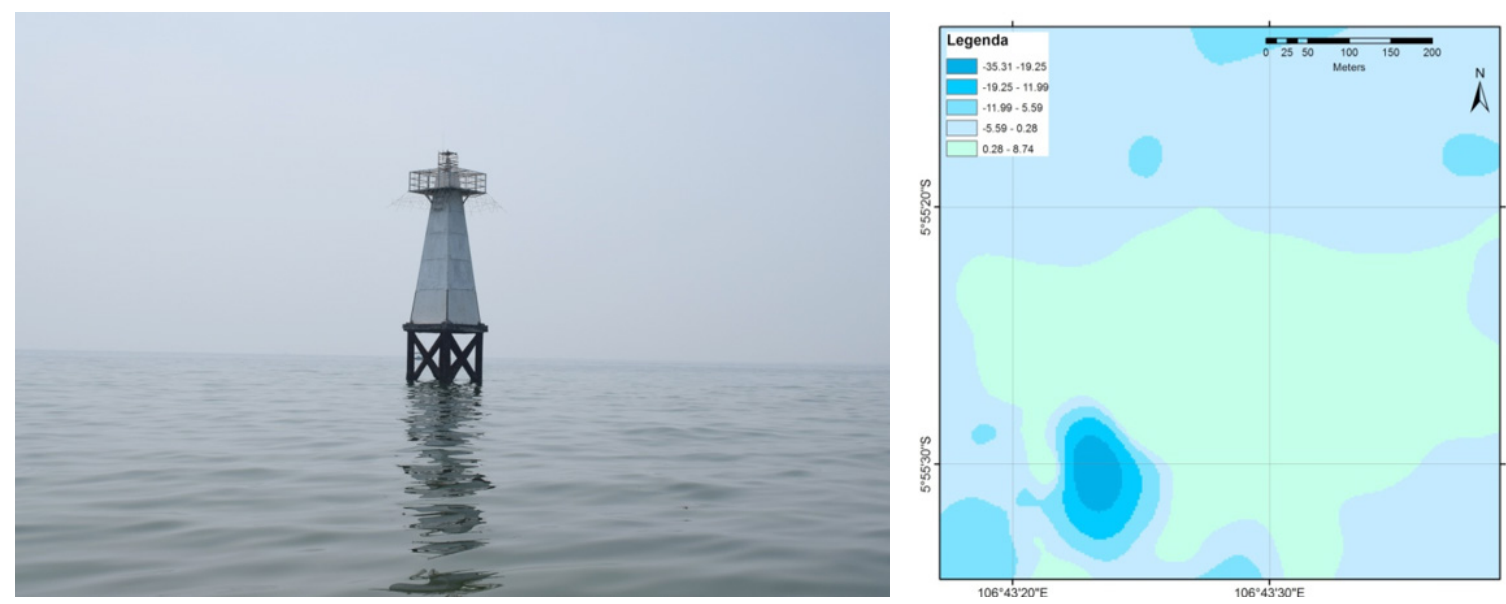

Gambar 7. Situasi dan kondisi kedalaman di sekitar lokasi Pulau Dapur.

DKI Jakarta

\section{UCAPAN TERIMA KASIH}

Ucapan terima kasih penulis sampaikan kepada Kepala Pusat Riset Kelautan BRSDM-KP yang telah mendanai survey identifikasi pulau tenggelam ini dengan DIPA tahun 2017. Serta kepada Dr. Semeidi Husrin sebagai koordinator kegiatan Teluk Jakarta 2017 yang telah memberikan data yang berharga. Juga kepada seluruh pihak yang telah membantu selama pelaksanaan survey, hingga kami dapat dengan selamat melakukan tugas di lapangan.

\section{DAFTAR PUSTAKA}

Anggraini, N., Trisakti, B., \& Soesilo, T.E.B. (2012). Pemanfaatan Data Satelit Untuk Analisis Potensi Genangan dan Dampak Kerusakan Akibat Kenaikan Muka Air Laut. Jurnal Penginderaan Jauh, Vol. (9)2: 140-151.

Arifin, T., Pranowo, W. P., \& Zulham, A. (2014). Dinamika Teluk Jakarta, Analisis Prediksi Dampak Pembangunan Tanggul Laut Jakarta (Jakarta Giant Sea Wall), Penerbit IPB Press, Bogor.

Bakosurtanal. (1992). Gazetteer : Nama-Nama Pulau Dan Kepulauan di Indonesia (Dok.No. 26/1992), Badan Koordinasi Survey dan Pemetaan Nasional, Cibinong.

Dahuri, R. (2013). Pengelolaan Pembangunan Pulaupulau Kecil Secara Optimal dan Berkelanjutan. Bahan Kuliah : Pengelolaan Sumberdaya Pulau-pulau Kecil. IPB. Bogor.
Husrin, S., Solehuddin, T., Prasetijo, R., Gunawan, D., Amri, S. N., Heriati, A. \& Mustikasari, E. (2018), The Mechanism of "Drowning" Small Islands in Kepulauan Seribu, Poster on The 1st Joint Workshop on Marine Environment of Jakarta Bay: Scientific Networking for Environmental Studies, BPPT, Jakarta.

Rochman, D., Rais, J., Abidin, H. Z., \& Wedyanto, K. (2004). Land Subsidence of Jakarta Metropolitan Area, $3^{\text {rd }}$ FIG Regional Conference, Jakarta, Indonesia.

Setyawan, A., Fukuda, Y., Nishijima, J., \& Kazama, T. (2015). Detecting Land Subsidence Using Gravity Method in Jakarta and Bandung Area, Indonesia. Procedia Environmental Sciences, Vol. 23: 17 - 26.

Widodo, P. W. (2015). Penilaian Pulau Kecil Sebagai Dasar Pengembangan Investasi Ekowisata (Studi Kasus Pulau Pari, Pulau Payung Besar, dan Pulau Tidung Kecil Kabupaten Kepulauan Seribu, DKI Jakarta), Tesis, Sekolah Pascasarjana, Institut Pertanian Bogor, Bogor.

Zon, F. (2012). Hari Terakhir Kartosoewirjo, 81 Foto Eksekusi Imam DI/TII, Fadli Zon Library, Jakarta. 